\title{
ReSEARChArticle
}

\section{Some studies of medicinal pteridophytes in Kanpur urban, U.P.}

\author{
NIKHIL AGNIHOTRI
}

\section{SUMMARY}

Pteridophyta is a small but important group of plant world that is also known as non-flowering vascular plants. About 305 genra and 10000 species of pteridophyta are known till today. 191 genra and 1000 species of pteridophytes are known in India up to now. The medicinal utility of pteridophytes group of plants is known since very ancient times. Two of the ancient Indian medicine men namely Charak and Sushrut identified the medicinal utility of Marsilia and Adiantum. Similarly, Equisitum has also being used by the traditional healers since ages. The present study is based on the medicinal utility of pteridophyta plants found in Kanpur and nearby areas. In the study, the medicinal utility, their botanical names, their family names, habit and habitat, useful parts and usage of 8 plants belonging to 6 pteridophyte families found in Kanpur and adjacent areas have been listed. This study is an effort of listing the medicinal utility and preserving of pteridophytes for future use.

Key Words : Pteridophytes, Medicinal Plants, Traditional medicines

How to cite this article : Agnihotri, Nikhil (2016). Some studies of medicinal pteridophytes in Kanpur urban, U.P. Internat. J. Plant Sci., 11 (2): 315-317, DOI: 10.15740/HAS/IJPS/11.2/315-317.

Article chronicle : Received : 29.12.2015; Revised : 19.05.2016; Accepted : 21.06.2016

\section{AUTHOR FOR CORRESPONDENCE}

NIKHIL AGNIHOTRI, Department of Botany, Sri Deen Dayal

Kushwaha Mahavidyalaya, SAMBHALPUR (KANPUR) INDIA

Email: nikhil.azolla@gmail.com 